\title{
HEALTH IMPACT ASSESSMENT CASE STUDY: WORKING WITH LOCAL GOVERNMENT TO OBTAIN HEALTH BENEFITS
}

Sarah Thackway and Susan Furber

Population Health Division

South Eastern Sydney and Illawarra Area Health

Service

\section{Leonie Neville}

NSW Public Health Officer Training Program NSW Department of Health

This paper provides a brief overview of an intermediate health impact assessment (HIA) conducted collaboratively with local government. The focus is on the lessons learnt; the full details of the process and findings have been described elsewhere. ${ }^{1,2}$

\section{BACKGROUND TO THE HIA}

In 2001 the Illawarra Division of Population Health (in the former Illawarra Health) identified the broader environmental determinants of health as a service-wide priority. Environmental determinants were identified as those amenable to intervention, of regional interest and reliant on the development of strong intersectoral cooperation to achieve mutually desired outcomes between sectors: health and local government in particular.

This priority led to a number of inter-agency projects. However, one of the limitations identified as a barrier to effective intersectoral programs was the lack of staff trained in and with knowledge of HIA. Early in 2004 a strategic opportunity arose to address these limitations when, concurrent to Phase 2 of the NSW HIA Project (see Harris-Roxas and Simpson, 'The NSW Health Impact Assessment Project', in this issue), a local council released

\section{BOX 1}

\section{ADVICE TO OTHERS UNDERTAKING AN INTERMEDIATE HIA, BASED ON LESSONS LEARNT WHILE UNDERTAKING AN HIA ON THE SHELLHARBOUR FORESHORE MANAGEMENT PLAN}

We recommend that others undertaking an intermediate HIA:

1. gain commitment from senior management from each organisation to ensure access to people with the range of skills required for undertaking an HIA

2. follow a step-wise approach to conducting an HIA

3. establish a steering committee with representatives from each organisation and relevant body

4. ensure at least one person on the Steering Committee has undertaken training, or has experience, in conducting an HIA

5. dedicate a project manager to the HIA who can commit significant time to the process

6. be aware of the time and resources required when undertaking an HIA. a management plan that aimed to conserve and beautify an area of foreshore while encouraging and supporting appropriate public use. The Illawarra Division of Population Health and the Council agreed to conduct a collaborative six-month intermediate HIA on the plan.

\section{OVERVIEW OF THE HIA}

To drive the HIA and establish the supporting values a Steering Committee was established. The Committee included representation from the Council (a social planner and an environmental health officer) and the Area Health Service (public health and health promotion staff) and undertook a step-wise process of screening, scoping, assessment, negotiation and decision-making. During the scoping phase the Steering Committee acknowledged a broad definition of health. However, due to resource considerations and service priorities the health-related issues identified were limited to physical activity and social cohesion.

During the assessment phase the following were performed: a community profile, a literature review, a policy review, a recreational environment audit, and interviews with key informants. Differential impacts on population subgroups were considered.

A process whereby the evidence obtained during the assessment phase was weighted according to its relative contribution to the potential 'health impacts' supported the negotiation phase. This was undertaken using a typology of evidence matrix. Consensus was gained from the Steering Committee on the values placed on each source of evidence. For example, the findings from the key informants were deemed important in addressing questions on appropriateness, satisfaction, salience and acceptability. In contrast, the literature review was ranked highly when addressing questions of effectiveness.

To assist in the decision-making phase, priority matrices were applied for each initiative in the management plan, which considered the nature, likelihood and relative size of the potential health impacts. This enabled the Steering Committee to prioritise particular aspects of the plan.

The final report provided a summary of findings, a prioritisation for the implementation of different aspects of the plan and options to maximise the potential positive and minimise the potential negative impacts. The findings were presented to the Mayor at a Council meeting.

\section{BENEFITS AND BARRIERS}

A process evaluation was conducted to reflect upon the value and feasibility of conducting a HIA on the plan. The HIA was generally well received by Council and members of the Steering Committee. There were many lessons learnt (see Box 1), one being that considerable resources, skills and knowledge are required to conduct intermediate HIAs. 
Indeed, the resources required to conduct an HIA and the likely outcomes need to be weighed by managers prior to embarking upon an HIA. An important part of the screening process should be consideration of the balance between the resources required to undertake the HIA and the likelihood of influencing outcomes and affecting significant health gain. Indeed, the resource issue is critical to the viability of integrating HIA into core health service activities.

The HIA did, however, provide a useful framework for strengthening the collaborative relationship between the Council and the Division of Population Health. It improved both organisations' understanding of each other's business, the broader definition of health and, specifically, the inter-relationship between the environment and physical activity and social cohesion. The process also helped to up-skill staff and facilitated the sharing of information and resources. Successful completion of the project also led to ongoing local developments, including a current HIA using a different methodology with a different local council. This current HIA is being conducted on a capital works program with similar environmental features and aims to assess and compare HIA methodologies (desk-based versus intermediate) with a view to evaluating the feasibility of methods and providing recommendations on when to apply particular approaches.

\section{REFERENCES}

1. Neville L, Furber S, Thackway S. et al. A health impact assessment of an environmental management plan: The impacts on physical activity and social cohesion. Health Promotion Journal of Australia. (Accepted for publication, 2005.)

2. Neville L, Furber S, Thackway S, Wallin T, Gray E, Mayne D et al. Health impact assessment on the Shellharbour Foreshore Management Plan, Illawarra Area Health Service and Shellharbour Council, 2004. Available at http://chetre.med. unsw.edu.au/files/IAHS_Final_HIA_Report.pdf .

\section{HEALTH IMPACT ASSESSMENT ON AN INTEGRATED CHRONIC DISEASE PREVENTION CAMPAIGN}

\author{
Blythe O'Hara, Jenny Hughes and Paul Kehoe \\ Centre for Chronic Disease Prevention and \\ Health Advancement \\ NSW Department of Health \\ Hannah Baird \\ National Prescribing Service Ltd \\ Therese Milham \\ Health Services Policy Branch \\ NSW Department of Health
}

\section{Sharon Hills}

Access Solutions

A priority in the NSW Chronic Disease Prevention Strategy 2003-2007 is to: Design, test, develop and evaluate a state-based pilot of an overarching 'integration' strategy to draw together existing programs and activities dealing with tobacco, alcohol, nutrition, physical activity and mental health promotion with a view to progressing state-wide implementation if the evaluation results are favourable.

It is proposed that this priority be addressed through a chronic disease prevention campaign promoting changes in knowledge, attitudes and practices on contributory risk factors to decrease the prevalence of chronic disease among 35-55 year olds. For the purposes of this campaign, chronic diseases include cardiovascular diseases, cancers, chronic lung diseases and type 2 diabetes.

The proposed campaign underwent a health impact assessment (HIA) between February and October 2004 by the Health Promotion Strategies and Settings Branch in the NSW Department of Health's Centre for Chronic Disease Prevention and Health Advancement.

\section{WHAT WAS DONE}

The HIA of the proposed chronic disease prevention campaign was undertaken using the procedures described by Scott-Samuel et al: screening, scoping, assessment, negotiation and decision making, and evaluation. ${ }^{2}$

\section{WHAT WAS FOUND}

Screening identified that the proposed campaign was suitable for an HIA: it was in an early stage of development and so able to be influenced by recommendations; it had a well-defined program structure of aims, goals, and targets; and there were indications from available evidence that the proposed strategies of social marketing and complementary initiatives would have a positive effect in reducing the risk of chronic disease.

As part of the scoping phase an existing, informal steering group for the HIA was formally appointed as such. It included representation from the Centre for Chronic Disease Prevention and Health Advancement, the Centre for Aboriginal Health, and Population Health from the then Wentworth Area Health Service. Key questions identified for the HIA were (i) Are lifestyle risk factor campaigns effective at changing behaviours? and (ii) Are population subgroups differently affected by lifestyle campaigns? Data type and sources to answer these questions were identified, and included NSW population health data, literature reviews, and the opinion of key informants.

Assessment of the sources of data determined that the NSW population is at risk of chronic disease arising from the identified risk factors; that health status and 